\title{
Design and experiment of the comb-brush harvesting machine with variable spacing for oil-tea camellia fruit
}

\author{
Xiaoqiang $\mathrm{Du}^{1,2^{*}}$, Tengfei Shen ${ }^{1}$, Lijun Zhao ${ }^{3}$, Guofeng Zhang ${ }^{1,2}$, Anguo $\mathrm{Hu}^{4}$, \\ Shenggao Fang $^{5}$, Yongqing $\mathrm{Cao}^{6}$, Xiaohua $\mathrm{Yao}^{6}$ \\ (1. School of Mechanical Engineering \& Automation, Zhejiang Sci-Tech University, Hangzhou 310018, China; \\ 2. Zhejiang Province Key Laboratory of Transplanting Equipment and Technology, Hangzhou 310018, China; \\ 3. College of Intelligent and Manufacturing Engineering, Chongqing University of Arts and Sciences, Chongqing 402160, China; \\ 4. Yongkang Valid Technology Co., Ltd., Yongkang 321300, Zhejiang, China; \\ 5. Dongfanghong Forest Farm, Jinhua 321000, Zhejiang, China; \\ 6. Research Institute of Subtropical Forestry, Chinese Academy of Forestry, Hangzhou 311400, China)
}

\begin{abstract}
Oil-tea camellia tree is an important oil plant in China that has long flexible branches. The most challenging feature for the mechanized harvest of oil-tea fruits is that its flower and fruit grow synchronously. In order to improve the harvesting efficiency and avoid damaging the flower bud, a hand-held fruit harvesting machine with a variable spacing comb brush was proposed. The harvesting machine can generate three kinds of actuation to detach fruit when it runs. The main actuation results from the brushing of multiple comb fingers. The other two kinds of actuation result from the beating of comb fingers on the fruits and the branches. The finger spacing of the comb brush can be adjusted consequently through moving the spacing adjusting crossbar. Hence, when the finger spacing is smaller than the diameter of the oil-tea fruit, the fruit is brushed off, but the flower bud and leaf pass through the finger gap. When the finger spacing is bigger than the fruit diameter, the fruit stuck between the fingers is loosened to ensure the continuous operation of the machine. Nylon was used as the material of the brush finger to avoid damage, which can also reduce the overall weight. The dynamic simulation of the harvesting machine was carried out with ADAMS, and the acceleration of the front end of the comb finger and the variation of the finger spacing were analyzed. The prototype of the harvesting machine was built and tested in the field. Field experiment results showed that when the speed of the comb finger drive shaft was $480 \mathrm{r} / \mathrm{min}$, the average harvesting percentage of oil-tea fruit was $80 \%$, and the flower bud was seldom detached, which met the working requirements of oil-tea fruit harvesting.
\end{abstract}

Keywords: oil-tea camellia fruit, harvesting machine, variable spacing, comb brush, simulation analysis DOI: $10.25165 /$ j.ijabe.20211401.5703

Citation: Du X Q, Shen T F, Zhao L J, Zhang G F, Hu A G, Fang S G, et al. Design and experiment of the comb-brush harvesting machine with variable spacing for oil-tea camellia fruit. Int J Agric \& Biol Eng, 2021; 14(1): 172-177.

\section{Introduction}

Oil-tea camellia is a unique woody edible oil plant species in China. It is also known as one of the world's four woody oil plants, together with olive, oil palm and coconut. Tea oil is known as oriental olive oil, which has been listed as a high-level healthy edible oil by Food and Agriculture Organization of the United Nations ${ }^{[1-3]}$. Oil-tea fruit needs to be harvested in time due to its short suitable processing period ${ }^{[4]}$. Oil-tea fruit and flower

Received date: 2020-01-23 Accepted date: 2020-08-17

Biographies: Tengfei Shen, Master candidate, research interest: mechanical design and theory, Email: 906963688@qq.com; Lijun Zhao, PhD, Senior Engineer, research interest: intelligent manufacturing, Email: 20190005@ cqwu.edu.cn; Guofeng Zhang, PhD, Professor, research interest: agricultural machinery, Email: zhguof@zstu.edu.cn; Anguo Hu, Engineer, research interest: agricultural machinery, Email: rd02@validtools.com; Shenggao Fang, Engineer, research interest: oil-tea camellia cultivation, Email: 2143641264@qq.com; Yongqing Cao, $\mathrm{PhD}$, Research Associate, research interest: oil-tea camellia cultivation, Email: caorq1981@163.com; Xiaohua Yao, PhD, Research Fellow, research interest: oil-tea camellia cultivation, Email: yaoxh168@163.com.

*Corresponding author: Xiaoqiang $\mathrm{Du}, \mathrm{PhD}$, Professor, research interest: mechanical design and theory. School of Mechanical Engineering \& Automation, Zhejiang Sci-Tech University, No. 928, Second Avenue, Xiasha Higher Education Zone, Hangzhou 310018, China. Tel: +86-13588209025, Email: xqiangdu@zstu.edu.cn. grow synchronously, so it is necessary to avoid damaging flower buds during harvesting ${ }^{[5]}$. Oil-tea camellia is mainly planted in hilly and mountainous areas, and most oil-tea camellia trees are not planted in a standardized mode. Therefore, the oil-tea fruit mainly depends on manual picking, which costs a large amount of labor and has low efficiency ${ }^{[6]}$.

The research on oil-tea fruit harvester in China is an emerging hot topic in recent years due to the increasing planting area scale. The technology applied to mechanized harvest of oil-tea fruit is mostly vibration which has reached success on cherry ${ }^{[7]}$, olive ${ }^{[8,9]}$, Chinese hickory nuts ${ }^{[10]}$, blueberry ${ }^{[11,12]}$, grape ${ }^{[13]}$, and other fruit. Typical examples are the trunk shaker ${ }^{[14]}$, the canopy shaker ${ }^{[15]}$, the side-pass comb harvester ${ }^{[16]}$, and the straddle harvester ${ }^{[17]}$. But these large harvesters are not suitable for hilly and mountainous areas and are difficult to be widely promoted.

In order to improve the picking efficiency, domestic scholars have done a lot of meaningful exploration and research on hand-held canopy shaker, which is a promising solution to oil-tea fruit mechanical harvest. For example, Luo et al. ${ }^{[18]}$ designed a kind of tooth-comb type device for oil-tea fruits picking, which realized semi-mechanized picking of oil-tea fruits. Gao et al. ${ }^{[19]}$ designed another tooth-comb type picking machine, and the key design was the rotary picking head and the picking arm of the machine. Rao et al. ${ }^{[20]}$ designed a kind of motor-driven picking 
actuator with a rotating rubber roller, and oil-tea fruit would fall off when it collided with the upper and lower rotating rubber rollers. However, these machines have various problems, such as poor picking efficiency, damage to flower buds, etc. Therefore, there is no commercialized machine for harvesting oil-tea fruits at present.

In this study, a hand-held oil-tea fruit harvesting machine with variable spacing comb brush was designed, which can be operated by workers in hilly areas and effectively get the fruit detached from the tree with little damage to the flower buds. The machine has a similar structure with the hand-held comb-brush olive shaker designed by Minelli ${ }^{[21]}$, but can realize the periodic change of the finger spacing to prevent the fruit from being stuck between the fingers. At the same time, this machine can generate three kinds of actuation to detach fruit, which increases the possibility of fruit detachment. The main actuation resulted from the brushing of multiple comb fingers. The other two kinds of actuation resulted from the beating of comb fingers on the fruits and the branches. The dynamic simulation of the harvesting machine was carried out using ADAMS, by which the range of working parameters was obtained. On this basis, field experiments were carried out to verify the feasibility of harvesting oil-tea fruits using the developed comb-brush harvesting machine.

\section{Materials and methods}

\subsection{Physical characteristics of the oil-tea camellia}

The physical characteristics of the oil-tea camellia were investigated at the Dongfanghong oil-tea camellia orchard, Jinhua City, Zhejiang Province, China. The oil-tea camellia variety tested is Changlin series which is the most popular variety in Zhejiang Province. The experiment was carried out in October 2018 when the Changlin oil-tea fruit was mature and ready for harvest. The oil-tea camellia trees have long flexible branches, and the flower and fruit are mainly distributed around the surface of the canopy. The investigation shows that the oil-tea fruits are mostly distributed within the layer of $500 \mathrm{~mm}$ away from the surface of the canopy. The lateral and longitudinal detachment force of the oil-tea fruits were measured ${ }^{[22,23]}$ by a force gauge (HP-50, Yueqing Aidebao Instrument Co., Ltd., Yueqing, Zhejiang, China) and a self-made measuring fixture, as shown in Figure 1. The specifications of the force gauge are listed in Table 1.

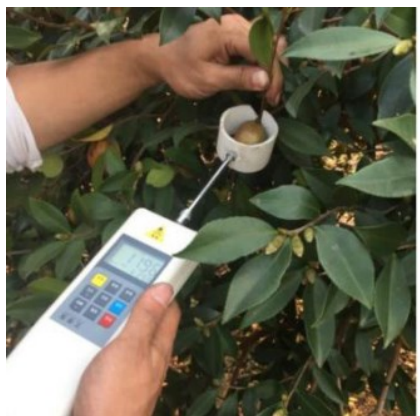

a. Longitudinal detachment force

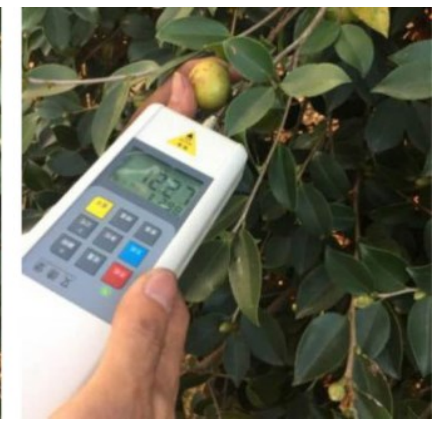

b. Lateral detachment force
Figure 1 Measurement of the detachment force of fruit

Table 1 Specifications of the force gauge

\begin{tabular}{cccc}
\hline Model & Capacity/N & Resolution $/ \mathrm{N}$ & Accuracy/\% \\
\hline HP-50 & 50 & 0.01 & \pm 0.5 \\
\hline
\end{tabular}

The flower bud was cone-shaped and attached to small branches without stem, so only the longitudinal detachment force of the flower bud was measured. The diameters of oil-tea fruit and flower bud were measured by digital vernier caliper (range: $200 \mathrm{~mm}$; accuracy: $0.02 \mathrm{~mm}$ ), and the weights of oil-tea fruit and flower bud were recorded by electronic balance (range: $500 \mathrm{~g}$; accuracy: $0.01 \mathrm{~g}$ ). Several oil-tea camellia trees were randomly selected, and a total of 50 oil-tea fruits in different positions of the trees were measured. Table 2 shows the physical characteristics of the oil-tea fruit and flower bud.

Table 2 Physical characteristics of the oil-tea fruit and flower bud

\begin{tabular}{|c|c|c|c|c|c|c|c|}
\hline $\begin{array}{l}\text { Long diameter } \\
\text { of the } \mathrm{bud} / \mathrm{mm}\end{array}$ & $\begin{array}{l}\text { Short diameter } \\
\text { of the bud } / \mathrm{mm}\end{array}$ & $\begin{array}{l}\text { Weight of the } \\
\text { bud } / \mathrm{g}\end{array}$ & $\begin{array}{l}\text { Longitudinal detachment } \\
\text { force of the bud/N }\end{array}$ & $\begin{array}{l}\text { Diameter of the } \\
\text { fruit } / \mathrm{mm}\end{array}$ & $\begin{array}{l}\text { Weight of the } \\
\text { fruit/g }\end{array}$ & $\begin{array}{l}\text { Longitudinal detachment } \\
\text { force of the fruit } / \mathrm{N}\end{array}$ & $\begin{array}{l}\text { Lateral detachment } \\
\text { force of the fruit } / \mathrm{N}\end{array}$ \\
\hline $16.13 \pm 1.47$ & $8.56 \pm 0.57$ & $0.55 \pm 0.11$ & $6.38 \pm 2.83$ & $31.89 \pm 5.00$ & $18.63 \pm 7.03$ & $14.03 \pm 8.19$ & $18.11 \pm 8.58$ \\
\hline
\end{tabular}

Note: The data in the table represents Mean \pm SD.

It can be seen from Table 2 that the flower bud is smaller than the fruit, where the average diameter of the oil-tea fruit is $31.89 \mathrm{~mm}$. The average longitudinal detachment force of the oil-tea fruit, which is $14.03 \mathrm{~N}$, is smaller than the average lateral detachment force which is $18.11 \mathrm{~N}$. Furthermore, the average longitudinal detachment force of the oil-tea fruit is significantly greater than that of the flower bud. Therefore, the flower bud is more likely to detach than the fruit when the oil-tea tree canopy is subjected to vibration. Due to the great difference in the size and detachment force between the oil-tea fruit and flower bud, a comb-brush harvesting machine can be used ${ }^{[24]}$. By selecting the proper finger spacing, the flower bud and the leaf could pass through the finger gap, but the fruit will be stopped by the finger and detached by the actuation force. Because the average longitudinal detachment force of the oil-tea fruit is smaller than the average lateral one, the movement direction of the comb brush is preferably longitudinal.

\subsection{Structure of the comb-brush harvesting machine}

The structure of the oil-tea fruit harvesting machine with variable spacing comb brush is shown in Figure 2a. The harvesting machine adopts double comb-brush actuators as shown in Figure 2b, which increases the working area and may improve the working efficiency. The comb-brush actuator consists of a transmission part, a fixing part and two comb brushes. The transmission part includes comb finger drive shaft 7 , pinion gear 8 , large gear 9 and input shaft 14 . The comb finger drive shaft has an inclined end portion. The fixing part includes split pin 2, cylindrical pin 4 , hexagon flange bolt 5 , crossbar fixing block 6 , the support rod 13, and gearbox 10. Both sides of the crossbar fixing block are equipped with bearings, and the hexagon flange bolt is tightened with the inner screw hole of the outer end face of the comb finger drive shaft. Each comb brush includes link 1, comb finger 3, brush crossbar 11 and spacing adjusting crossbar 12 . Each comb finger is connected with the brush crossbar through a cylindrical pin.

When the machine runs, the two comb finger drive shafts rotate simultaneously due to the gear pair in the gearbox. The brush crossbars with the comb fingers installed swing with the rotation of the shafts consequently. The whole group of comb fingers installed on the brush crossbars also moves with the corresponding amplitude of the brush crossbars. Because of the link connecting with the supporting rod, the spacing adjusting crossbars are driven to slide back and forth by the moving comb 
fingers. Because the spacing between the holes on the spacing adjusting crossbar is fixed, with the movement of the comb fingers and the spacing adjusting crossbars, the finger spacing of the comb brush changes consequently. In this way, the operation of the harvesting machine is realized.
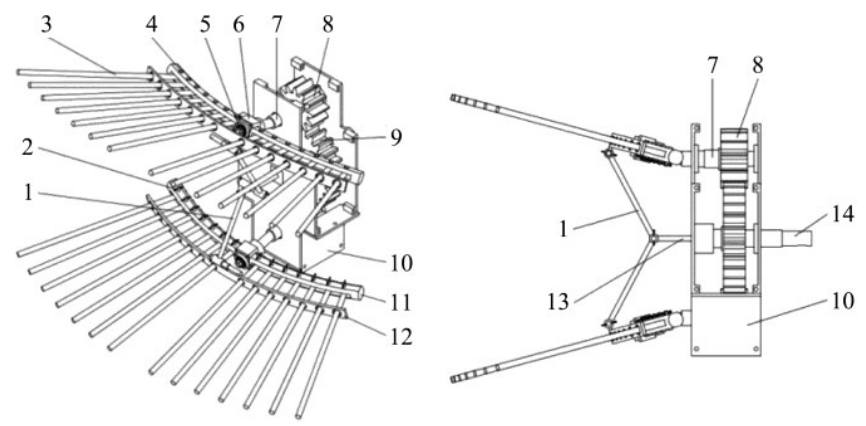

1. Link 2. Split pin 3. Comb finger 4. Cylindrical pin 5. Hexagon flange bolt 6. Crossbar fixing block 7. Comb finger drive shaft 8. Pinion gear 9. Large gear 10. Gearbox 11. Brush crossbar 12. Spacing adjusting crossbar 13. Support rod 14. Input shaft a. The comb-brush actuator

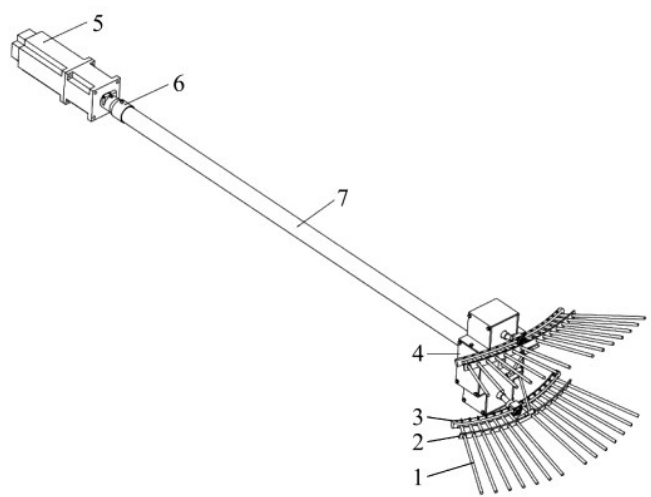

1. Comb finger 2. Spacing adjusting crossbar 3. Brush crossbar 4. Gearbox

5. Electric motor 6. Motor joint 7. Drive rod

b. The comb-brush harvesting machine

Figure 2 Structure diagram of the comb-brush harvesting machine

\subsection{Design of the comb fingers with variable spacing}

As shown in Figure 3, the brush crossbar to support the comb fingers is arc-shaped. The comb finger is connected with the brush crossbar through a cylindrical pin. Both sides of the crossbar fixing block are equipped with bearings, and the crossbar fixing block rotatably positions the brush crossbar at the end of the comb finger drive shaft. The hexagon flange bolt is tightened with the inner screw hole at the end of the comb finger drive shaft so that the comb finger drive shaft drives the brush crossbar to rotate without slipping off. The spacing adjusting crossbar is arc-shaped as well, and a number of through-holes are arranged at equal spacing on both sides. The comb fingers are all inserted through the holes. Under the combined force of the whole set of comb fingers, the spacing adjusting crossbar slides back and forth along the comb fingers. In order to reduce the impact and the weight, nylon is used as the material of the comb fingers. The length of the comb finger is $300 \mathrm{~mm}$ and the diameter is $8 \mathrm{~mm}$.

The length of the comb finger is much longer than its reciprocating sliding distance. As the position of the hole on the spacing adjusting crossbar is fixed, with the back and forth movement of the spacing adjusting crossbar, the finger spacing of the comb brush changes consequently, as shown in Figure 4. As $d_{1}$ is shown in Figure 4, the finger spacing becomes greater when the spacing adjusting crossbar is close to the brush crossbar. As $d_{2}$ shown in Figure 4, the finger spacing becomes smaller when the spacing adjusting crossbar is far away from the brush crossbar.

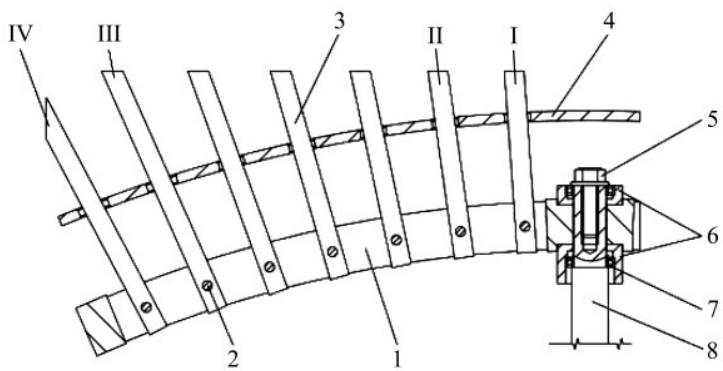

1. Brush crossbar 2. Cylindrical pin 3. Comb finger 4. Spacing adjusting crossbar 5. Hexagon flange bolt 6. Crossbar fixing block 7. Bearing 8. Comb finger drive shaft

Figure 3 Partial structure diagram of the comb fingers

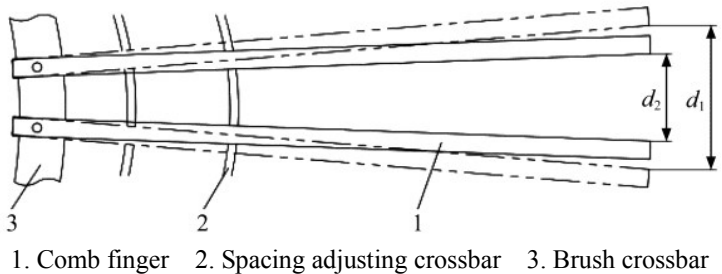

Figure 4 Spacing adjusting process of comb fingers

\subsection{Working principle of the comb-bush harvesting machine}

The comb-brush harvesting machine can generate three kinds of actuation to detach fruit when it runs. The main actuation resulted from the brushing of multiple comb fingers. The finger spacing of the comb brush changes can be adjusted consequently through moving the spacing adjusting crossbar. When the finger spacing is smaller than the diameter of the fruit, the fruit cannot pass through the finger gap and is detached by the fingers. When the finger spacing is bigger than the fruit diameter, the fruit stuck between the fingers will be loosened to ensure the continuous operation of the machine. The flower bud and leaf can pass through the finger gap all the time. Force analysis diagram between the fruit and fingers is shown in Figure 5.

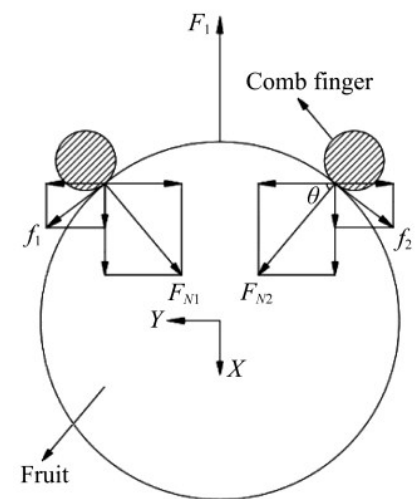

Figure 5 Force analysis diagram between the fruit and fingers

The comb finger applies pressure $F_{N}$ pointing to the center of the fruit and friction force $f$ tangential to the contact surface. When the combined force of pressure $F_{N}$ and friction $f$ is greater than the binding force $F_{1}$ between the fruit stem and the branch, the fruit can be pulled off ${ }^{[20]}$. The forces between the fruit and fingers are represented by Equations (1)-(4).

$$
\begin{gathered}
f=\mu F_{N} \\
F_{N 1}=F_{N 2} \\
F_{X}=F_{N 1} \sin \theta+F_{N 2} \sin \theta+f_{1} \cos \theta+f_{2} \cos \theta \\
F_{1} \leq F_{X}
\end{gathered}
$$

where, $F_{N}$ is the positive pressure that the comb finger applies to 
the fruit, $\mathrm{N} ; \mu$ is the friction coefficient between the fruit surface and comb finger, which is $0.3^{[25]} ; f$ is the friction force caused by the contact between the comb fingers and the fruit surface, $\mathrm{N} ; F_{X}$ is the combined force of pressure $F_{N}$ and friction $f$ along the $X$-axis, N; $\theta$ is the angle between $F_{N}$ and $Y$-axis, $\left(^{\circ}\right)$.

The other two actuation result from the beating of comb fingers on the fruits and the branches. During the movement of the comb brush, the comb fingers may hit the fruit, and those fruits of less binding force will fall. The comb fingers may beat the branches as well, which causes the branches to vibrate and the fruit or flower bud on the branch will vibrate consequently. When the inertia force of the fruits is greater than the binding force, the fruits are detached ${ }^{[26,27]}$

\subsection{Simulation analysis of the comb-brush actuator}

In order to make the finger spacing and the acceleration of the comb fingers meet the requirements of oil-tea fruit harvesting, ADAMS 2014 was used to perform dynamic simulation of the comb-brush actuator to obtain reasonable parameters. Firstly, the 3D model of the comb-brush actuator was created in SolidWorks 2016. To accelerate the simulation, the model of the actuator was simplified by neglecting some accessory parts such as bolts, bearings, and split pins. The 3D model consisting of the transmission part, the fixing part and the comb-brush part, was imported into ADAMS for dynamic simulation analysis, as shown in Figure 6. Joint elements were specified for each connection: set fixed pair between gearbox and earth, gearbox and support rod, input shaft and big gear, comb finger drive shaft and pinion gear, brush crossbar and cylindrical pin; set rotating pair between the input shaft and gearbox, comb finger drive shaft and gearbox, comb finger drive shaft and brush crossbar, cylindrical pin and comb finger, spacing adjusting crossbar and link, support rod and link; set gear pair between big gear and pinion gear; set moving pair between comb finger and spacing adjusting crossbar. The power was input by the input shaft to drive the movement of the comb fingers. After the pre-processing of the constraint, motion and material property, the simulation was conducted for $0.5 \mathrm{~s}$ duration and 200 steps. Finally, the acceleration and finger spacing variation with the rotation of the comb finger drive shaft were analyzed.

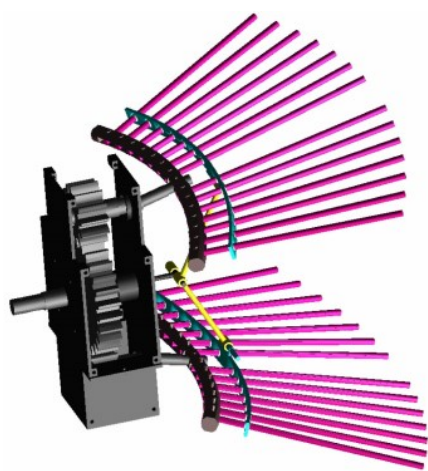

Figure 6 Simulation model of the comb-brush actuator in ADAMS

\subsection{Field harvesting test}

Based on the design and simulation, an oil-tea fruit harvesting machine prototype with variable spacing comb brush was developed and field harvesting tests were carried out at the Dongfanghong oil-tea camellia orchard, Jinhua, Zhejiang Province, China from October 24 to 25, 2019. The test Changlin oil-tea fruit was ready for harvest. The test equipment includes the designed oil-tea fruit harvesting machine prototype and the designed self-propelled inverted-umbrella type fruit collector which could cover a three-meter wide canopy at most.

It can be seen from Table 2 that the weight of oil-tea fruit has high standard deviation. The counting method was used in this study to calculate the harvesting percentage ${ }^{[28,29]}$, which was represented by Equation (5).

$$
R=\frac{Q_{a}}{Q_{a}+Q_{n}} \times 100 \%
$$

where, $R$ is the harvesting percentage of oil-tea fruit, $\% ; Q_{a}$ is the number of detached fruits; $Q_{n}$ is the number of undetached fruits.

After recording the number of detached fruits and the harvesting time on each tree, the harvesting efficiency of the machine is represented by Equation (6).

$$
V=\frac{Q_{a}}{T}
$$

where, $V$ is the harvesting efficiency of the machine; $T$ is the harvesting time of fruits on each tree, min.

The oil-tea flowers grow at the time when the fruits are mature, so damage to flower buds must be avoided when picking. The preliminary test showed that the damage of the comb-brush harvesting machine to the leaves and branches was very small, and the flower buds were dense on the oil-tea camellia tree of which only a few buds were detached by the machine, so only the number of detached flower buds was recorded as the evaluation index.

\section{Results and discussion}

\subsection{Simulation results and analysis}

The kinematics of the comb-brush actuator was simulated in ADAMS. Figure 7 shows the spacing variation between the comb fingers I, II, III and IV which are indicated in Figure 3. The results indicate that the comb-brush actuator can produce variable finger spacing driven by the constant rotation of the comb finger drive shaft. It can be seen from Figure 7 that the range of the finger spacing between the outermost ends of the comb fingers I and II is $25.3-38.8 \mathrm{~mm}$, and the range of the finger spacing between the outermost ends of III and IV is $25.3-53.7 \mathrm{~mm}$. These two finger spacings represent the two most extreme cases, namely, the central finger spacing and the outermost finger spacing. The finger spacing between other comb fingers falls between these two finger spacings. Therefore, the range of the finger spacing is determined to be $25.3-53.7 \mathrm{~mm}$ for the designed harvesting machine. It can be seen from Table 2 that the average diameter of the oil-tea fruit is $31.89 \mathrm{~mm}$ and the average long diameter of the flower bud is $16.13 \mathrm{~mm}$. So the largest finger spacing is larger than the average diameter of the oil-tea fruit. The smallest finger spacing is larger than the average long diameter of the flower bud, and smaller than the average diameter of the fruit, which meets the working requirements of oil-tea fruit harvesting.

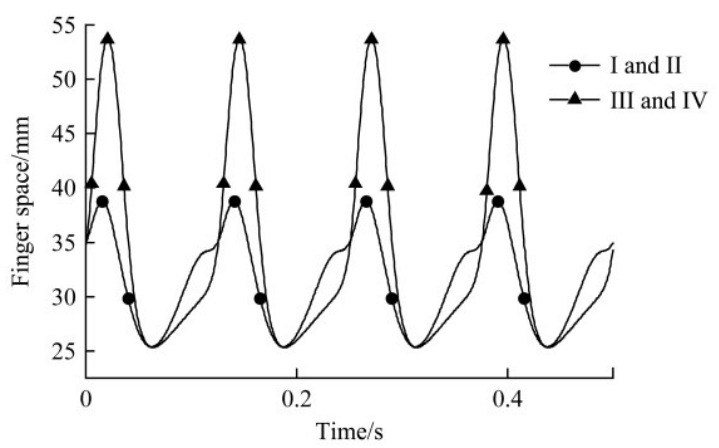

Figure 7 Spacing variation at the outermost ends of two pairs of comb fingers 
During the change of the finger spacing, comb fingers may hit the oil-tea fruit or branch at the same time. When the rotation speed of the comb finger drive shaft is too high, the damage to the flower buds, branches and leaves will increase. When the rotation speed is too low, the picking machine cannot effectively pick oil-tea fruit. Therefore, it is very important to select the appropriate rotation speed for fruit picking.

According to Table 2, the average diameter of oil-tea fruits is $31.89 \mathrm{~mm}$. Since the diameter of the brush finger is $8 \mathrm{~mm}$ and the smallest finger spacing is $25.3 \mathrm{~mm}$, the angle $\theta$ between the positive pressure $F_{\mathrm{N}}$ and $Y$-axis can be obtained according to Figure 5. Because the average longitudinal detachment force of the oil-tea fruit is $14.03 \mathrm{~N}$, substituting these data into Equations (1)-(4), $F_{N}$ can be calculated as $F_{N} \geq 6.84 \mathrm{~N}$.

The positive pressure $F_{N}$ resulted from the inertia force of the comb finger $m_{\text {finger }} a$, where $m_{\text {finger }}$ is the mass of the comb finger $(\mathrm{kg})$, and $a$ is the acceleration of the comb finger $\left(\mathrm{m} / \mathrm{s}^{2}\right)$. The density of nylon is $1300 \mathrm{~kg} / \mathrm{m}^{3}$, so the mass of the comb finger is $19.60 \mathrm{~g}$. Therefore, the acceleration of the comb finger can be calculated as $a \geq 348.98 \mathrm{~m} / \mathrm{s}^{2}$.

The ADAMS model of the comb-brush actuator was used to determine the rotation speed that meets the acceleration requirements. Figure 8 shows the acceleration at the outermost end of the comb finger I and IV when the speed of the comb finger drive shaft is set to $480 \mathrm{r} / \mathrm{min}$. The simulation results show that the maximum acceleration of comb finger I is $369.45 \mathrm{~m} / \mathrm{s}^{2}$ and the maximum acceleration of comb finger IV is $1118.12 \mathrm{~m} / \mathrm{s}^{2}$. The acceleration of the two comb fingers represents the two most extreme cases, while the acceleration of other comb fingers is between these two cases. Therefore, the range of the maximum acceleration is determined to be $369.45-1118.12 \mathrm{~m} / \mathrm{s}^{2}$. The results indicate that when the rotation speed is $480 \mathrm{r} / \mathrm{min}$, the comb fingers can detach the oil-tea fruit.

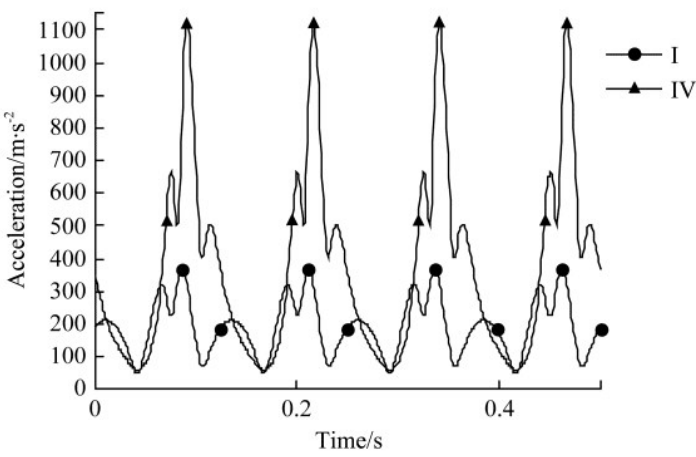

Figure 8 Acceleration of the outermost end of the comb fingers I and IV when the comb finger drive shaft is set to $480 \mathrm{r} / \mathrm{min}$

\subsection{Experiment results and analysis}

The developed comb-brush harvesting machine prototype is $2.5 \mathrm{~m}$ long and the weight is $5 \mathrm{~kg}$. The $350 \mathrm{~W}$ electric motor (6GU-300K, DC permanent magnet motor) was used to drive the actuator. Based on the simulation results, the speed of the comb finger drive shaft of the comb-brush harvesting machine prototype was set to $480 \mathrm{r} / \mathrm{min}$ in the experiment. In the field experiment, 10 oil-tea camellia trees were randomly selected for harvesting as shown in Figure 9.

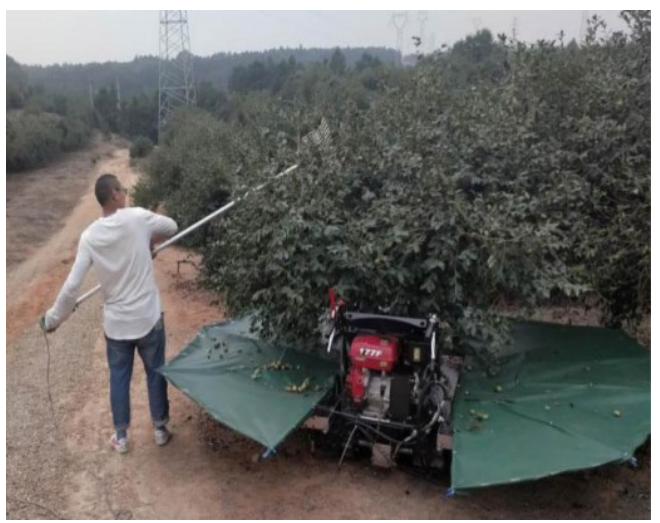

Figure 9 Field experiment of the comb-brush harvesting machine prototype

The experiment results of oil-tea fruit harvesting using the comb-brush harvesting machine prototype are shown in Table 3. It shows that the average number of detached flower buds is 29 , which means the machine has little damage to the yield of the following year. The experiment results show that the harvesting percentage of oil-tea fruit is more than $75 \%$, and the average harvesting percentage is $80 \%$. Therefore, the comb-brush harvesting machine with variable spacing can effectively harvest the oil-tea fruits with little damage to the flower buds due to the size difference between the fruit and the flower bud. Oil-tea trees are generally higher than $2.5 \mathrm{~m}$, so it is inconvenient to manually pick oil-tea fruits on the top. The developed harvesting machine overcomes this difficulty, and the oil-tea fruits at a high place can be easily detached by the machine, which highly reduces the labor intensity. The experiment results show that the harvesting efficiency of the oil-tea fruit is at least 36 fruits/min and the average harvesting efficiency is 46 fruits/min. According to the statistics of skilled pickers operation, the manual harvesting efficiency of the oil-tea fruit is about 14 fruits/min. By comparing with the manual harvesting efficiency, the harvesting efficiency of the machine is about 2.5-4 times that of the manual mode.

Table 3 Field experiment results of comb-brush harvesting machine prototype

\begin{tabular}{|c|c|c|c|c|c|c|}
\hline $\begin{array}{c}\text { Tree } \\
\text { sample }\end{array}$ & $\begin{array}{c}\text { The number of } \\
\text { detached oil-tea fruits }\end{array}$ & $\begin{array}{l}\text { The number of } \\
\text { undetached oil-tea fruits }\end{array}$ & $\begin{array}{l}\text { The number of detached } \\
\text { oil-tea flower buds }\end{array}$ & $\begin{array}{l}\text { The harvesting time } \\
\text { on each tree }\end{array}$ & $\begin{array}{c}\text { The harvesting percentage } \\
\text { of oil-tea fruit } / \%\end{array}$ & $\begin{array}{l}\text { The harvesting efficiency of } \\
\text { oil-tea fruit/fruits } \cdot \mathrm{min}^{-1}\end{array}$ \\
\hline 1 & 184 & 61 & 15 & 4'30" & 75.1 & 41 \\
\hline 2 & 111 & 26 & 29 & 1'53" & 81.02 & 59 \\
\hline 3 & 94 & 18 & 18 & $2^{\prime} 10^{\prime \prime}$ & 83.93 & 43 \\
\hline 4 & 426 & 123 & 42 & 8'02" & 77.60 & 53 \\
\hline 5 & 142 & 21 & 52 & $3 ' 20 "$ & 87.12 & 43 \\
\hline 7 & 114 & 37 & 34 & 3'08" & 75.50 & 36 \\
\hline 8 & 227 & 51 & 28 & $4 ' 48^{\prime \prime}$ & 81.65 & 47 \\
\hline 9 & 50 & 13 & 18 & $120 "$ & 79.37 & 38 \\
\hline 10 & 99 & 17 & 34 & $2^{\prime} 20^{\prime \prime}$ & 85.34 & 42 \\
\hline Average & 156 & 39 & 29 & $3^{\prime} 40^{\prime \prime}$ & 80 & 46 \\
\hline
\end{tabular}

Note: In the harvesting time, ' represents minutes and " represents seconds. 


\section{Conclusions}

The physical characteristics of the oil-tea camellia were measured, and it was found that the diameter of flower bud and oil-tea fruit were significantly different, so the comb-brush harvesting machine with variable spacing of fingers was designed in this study.

The picking machine can generate three kinds of actuation to pick fruit when it runs. The main actuation results from the brushing of multiple comb fingers. The physical characteristics measurement shows that the average longitudinal detachment force of oil-tea fruit is smaller than the lateral force, so the actuation of the comb brush is preferred to pulling the fruit. When the fruit cannot pass through the finger gap, comb fingers will pull the fruit off when the combined force of pressure and friction is greater than the detachment force of fruit. When the finger spacing is adjusted to be bigger than the fruit diameter, the fruit stuck between the fingers will be loosened to ensure the continuous operation of the machine. The flower bud and leaf can pass through the finger gap all the time. Based on the ADAMS simulation analysis, the range of finger spacing is $25.3-53.7 \mathrm{~mm}$, which meets the working requirements of oil-tea fruit harvesting. When the rotation speed of the comb finger drive shaft is $480 \mathrm{r} / \mathrm{min}$, the range of the maximum acceleration of the comb fingers is determined to be $369.45-1118.12 \mathrm{~m} / \mathrm{s}^{2}$, which can detach the oil-tea fruit.

A prototype of the comb-brush picking machine with variable spacing was assembled and tested in the field. Field experiment results showed that when the speed of the comb finger drive shaft was $480 \mathrm{r} / \mathrm{min}$, the average harvesting percentage of oil-tea fruit was about $80 \%$, and the detached flower bud was few, which had little effect on the yield of next year. The developed picking machine could highly improve the harvesting efficiency which was 2.5-4.0 times of the manual harvesting mode.

\section{Acknowledgements}

This work was supported by the Zhejiang Provincial Key Research \& Development Plan (Grant No. 2019C02065), the National Natural Science Foundation of China (Grant No. 31971798), the National Key Research and Development Program of China (Grant No. 2019YFD1001602), the 521 Talent Plan of Zhejiang Sci-Tech University, and the Cultivation Project for Youth Discipline Leader in Zhejiang Provincial Institute.

\section{[References]}

[1] Rao H H, Huang D S, Wang Y L, Chen B, Liu M H. Design and experiment of hydraulic-driven camellia fruit picking machine. Transactions of the CSAM, 2019; 50(5): 133-147. (in Chinese)

[2] Feng H X, Sam R, Jiang L Z, Li Y, Cao W M. High-performance size-exclusion chromatography studies on the formation and distribution of polar compounds in camellia seed oil during heating. Journal of Zhejiang University-Science B, 2016; 17(11): 882-891.

[3] Yao X H, Zhu Y X. The efficacy and application of camellia seed oil. Flavour Fragrance Cosmetics, 2018; 5: 74-78. (in Chinese)

[4] Huang D S, Rao H H. Research status and thinking on mechanized picking equipment of Camellia oleifera fruit in China. Forestry Machinery \& Woodworking Equipment, 2019; 47(7): 11-13. (in Chinese)

[5] Wu J, Wang W W, Wei D, Wang Y P. Some issue and consideration of development of Camellia oleifera industry. Forestry Economics, 2010; 5: 84-87. (in Chinese)

[6] Feng G K, Rao H H, Xu P, Liu M H. Research status on picking equipment and technology of camellia fruit. Journal of Chinese Agricultural Mechanization, 2015; 5(36): 125-127. (in Chinese)

[7] Du X Q, Chen D, Zhang Q, Scharf P A, Whiting M D. Dynamic responses of sweet cherry trees under vibratory excitations. Biosystems
Engineering, 2012; 111: 305-314.

[8] Hoshyarmanesh H, Dastgerdi H. R, Ghodsi M, Khandan R, Zareinia K. Numerical and experimental vibration analysis of olive tree for optimal mechanized harvesting efficiency and productivity. Computers and Electronics in Agriculture, 2017; 132: 34-48.

[9] Fantozzi F, Bartocci P, D'Alessandro B, Testarmata F, Fantozzi P. Carbon footprint of truffle sauce in central Italy by direct measurement of energy consumption of different olive harvesting techniques. Journal of Cleaner Production, 2015; 87: 188-196.

[10] Du X Q, Jiang F, Li S T, Xu N N, Li D W, Wu C Y. Design and experiment of vibratory harvesting mechanism for Chinese hickory nuts based on orthogonal eccentric masses. Computers and Electronics in Agriculture, 2019; 156: 178-186.

[11] Yu P C, Li C Y, Takeda F, Krewer G, Rains G, Hamrita T. Quantitative evaluation of a rotary blueberry mechanical harvester using a miniature instrumented sphere. Computers and Electronics in Agriculture, 2012; 88: 25-31.

[12] Yu P C, Li C Y, Takeda F, Krewer G, Rains G, Hamrita T. Measurement of mechanical impacts created by rotary, slapper, and sway blueberry mechanical harvesters. Computers and Electronics in Agriculture, 2014; 101: 84-92.

[13] Caprara C, Pezzi F. Measuring the stresses transmitted during mechanical grape harvesting. Biosystems Engineering, 2011; 110(2): 97-105.

[14] Rosa U A, Cheetancheri K G, Gliever C J, Lee S H, Thompson J, Slaughter D C. An electro-mechanical limb shaker for fruit thinning. Computers and Electronics in Agriculture, 2008; 61: 213-221.

[15] Savary S K J U, Ehsani R, Salyani M, Hebel M A, Bora G C. Study of force distribution in the citrus tree canopy during harvest using a continuous canopy shaker. Computers and Electronics in Agriculture, 2011; 76(1): 51-58.

[16] Sola-Guirado R R, Blanco-Roldan G L, Castro-Garcia S, Castillo-Ruiz F J, Gil-Ribes J A. Innovative circular path harvester for mechanical harvesting of irregular and large-canopy olive trees. Int J Agric \& Biol Eng, 2018; 11(3): 86-93

[17] Fu W, Zhang Z Y, Ding K, Cao W B, Kan Z, Pan J B, et al. Design and test of 4ZZ-4A2 full-hydraulic self-propelled jujube harvester. Int J Agric \& Biol Eng, 2018; 11(4): 104-110.

[18] Luo S T, Rao H H, Zhang L Y, Yu J J, Xu X Q, Li T, et al. Design and experiment of tooth comb type device for camellia fruits picking. Journal of Agricultural Mechanization Research, 2017; 39(2): 84-88. (in Chinese)

[19] Gao Z C, Li L J, Li X, Min S H, Yi C F. Development and test of picking actor in oil-tea camellia fruit picking machine of tooth comb type. Transactions of the CSAE, 2013; 29(10): 19-25. (in Chinese)

[20] Rao H H, Zhang L Y, Huang D S, Chen B, Liu M H. Design and test of motor-driven picking actuator of camellia fruit with rotate rubber roller. Transactions of the CSAM, 2018; 49(9): 115-121. (in Chinese)

[21] Minelli E. Apparatus for picking olives and the like. WO 2011/138058 A1.

[22] Castillo-Ruiz F J, Tombesi S, Farinelli D. Olive fruit detachment force against pulling and torsional stress. Spanish Journal of Agricultural Research, 2018; 16(1): 1-10.

[23] Fluck R C. Detachment of Tomato Fruit from Vines as Influenced by Fruit Maturity and Plant Desiccation. Transactions of the ASAE, 1970; 13(6): 704-707.

[24] Zhang W Q, Li Z Z, Tan Y Z, Li W. Optimal design and experiment on variable pacing combing brush picking device for Lycium barbarum. Transactions of the CSAM, 2018; 49(8): 83-90. (in Chinese)

[25] Rao H H, Luo S T, Yu J J, Zhang L Y, Liu M H. Study on simulation analysis of Camellia fruit picking and its bud damage with tooth comb dial knife machine based on ANSYS Workbench. Acta Agriculturae Zhejiangensis, 2017; 29(12): 2134-2141. (in Chinese)

[26] Hafezalkotob A, Hami-Dindar A, Rabie N, Hafezalkotob A. A decision support system for agricultural machines and equipment selection: A case study on olive harvester machines. Computers and Electronics in Agriculture, 2018; 148: 207-216.

[27] Pu Y J, Toudeshki A, Ehsani R, Yang F Z. Design and evaluation of a two-section canopy shaker with variable frequency for mechanical harvesting of citrus. Int J Agric \& Biol Eng, 2018; 11(5): 77-87.

[28] Cao C M, Zhan C, Sun Y, Li Z Z, Wu W T, Ding R. Design and experiment of portable walnut high-altitude pat-picking machine. Transactions of the CSAM, 2018; 49(3): 130-137. (in Chinese)

[29] Xu L M, Chen J W, Wu G, Yuan Q C, Ma S, Yu C C, et al. Design and operating parameter optimization of comb brush vibratory harvesting device for wolfberry. Transactions of the CSAE, 2018; 34(9): 75-82. (in Chinese) 